\title{
EVALUASI USER EXPERIENCE DENGAN PENDEKATAN USABILITY TESTING PADA SISTEM INFORMASI SMART ACADEMIC
}

\author{
Ria Andriani \\ Teknik Informatika, Universitas Amikom Yogyakarta, \\ Jl. Ring Road Utara, Condong Catur, Sleman, Yogyakarta \\ Email: ria@amikom.ac.id
}

(Diterima: 4 November 2019 ,direvisi: 12 Desember 2019, disetujui: 5 Agustus 2020 )

\begin{abstract}
Smart Academic is an information system used by administrative staff to manage administrative activities from upstream to downstream related to academia starting from the pre-lecture process such as Her-Registration of new students, filling in Study Plan Cards, and class division during the lecture process such as semester exams as well as the assessment process of each course, then proceed with administrative processing for the graduation until the graduation process, so that Smart Academic becomes a critical information system for the University if a failure occurs, it will hamper the lecture process which means the system cannot fulfill its objectives. This study evaluates the Smart Academic Information System through user experience with 8 respondents using the Usability Testing approach. This study examines user experience based on the Nielsen Heuristic method, namely Visibility of System, Match Between System and The Real World, User Control and Freedom, Consistency and standards, Preventive error system, Recognition Rather Than Recall, Flexibility and Efficiency, Aesthetic and Minimalist Design, Help User Recognize dialogue, and recovers from error, and Help and Documentation. Studies prove that of the 10 Nielsen Heuristic variables, 4 variables have poor Usability values, namely the Consistency and standards variable, Preventive error system, Aesthetic and Minimalist Design, and Help and Documentation
\end{abstract}

Keywords: information system evaluation, nielsen heuristic, usability testing

\begin{abstract}
ABSTRAK
Smart Academic merupakan sistem informasi yang digunakan oleh staf administrasi untuk mengelola aktifitas administratif dari hulu ke hilir yang berhubungan dengan akademik mulai dari proses sebelum perkuliahan seperti Her-Registrasi mahasiswa baru, pengisian Kartu Rencana Studi, dan pembagian kelas, selanjutnya saat proses perkuliahan seperti ujian semester serta proses penilaian masing-masing mata kuliah, kemudian dilanjutkan dengan pengolahan administrasi untuk yudisium sampai dengan proses wisuda, sehingga Smart Academic ini menjadi sistem informasi yang kritis bagi pihak Universitas apabila terjadi kegagalan maka akan menghambat proses perkuliahan yang artinya sistem ini tidak dapat memenuhi tujuannya. Penelitian ini melakukan evaluasi terhadap Sistem Informasi Smart Academic melalui pengalaman pengguna dengan jumlah responden sebanyak 8 orang dengan menggunakan pendekatan Usability Testing. Penelitian ini mengkaji pengalaman pengguna berdasarkan metode Nielsen Heuristic yaitu Visibility Of System, Match Between System And The Real World, User Control And Freedom, Consistency and standards, Preventive error system, Recognition Rather Than Recall, Flexibility and Efficient, Aesthetic and Minimalist Design, Help User Recognize dialogue, and recovers from error, dan Help and Documentation. Studi membuktikan bahwa dari 10 variabel Nielsen Heuristic terdapat 4 variabel yang memiliki nilai Usability kurang baik yaitu pada variabel Consistency and standards, Preventive error system, Aesthetic and Minimalist Design, dan Help and Documentation.
\end{abstract}

Kata Kunci: evaluasi sistem informasi, nielsen heuristic, usability testing

\section{PENDAHULUAN}

Penerapan sistem informasi dalam bidang akademik berfungsi untuk memantau seluruh kegiatan akademik yang berlangsung pada sebuah instansi pendidikan atau perguruan tinggi. DAAK 
(Direktorat Administrasi Akademik dan Kemahasiswaan) dalam proses pengelolaan Administrasi sudah menerapkan sistem informasi. Salah satunya adalah sistem informasi Smart Academic yang merupakan sebuah sistem berbasis desktop yang dibuat oleh Direktorat IC (Innovation Center) untuk menangani administrasi akademik yang digunakan oleh staf DAAK, sistem ini mulai diimplementasikan sejak tahun 2004.

Smart Academic merupakan sistem informasi yang digunakan oleh staf administrasi untuk mengelola aktifitas administratif dari hulu ke hilir yang berhubungan dengan akademik mulai dari proses sebelum perkuliahan seperti Her-Registrasi mahasiswa baru, pengisian Kartu Rencana Studi, dan pembagian kelas, selanjutnya saat proses perkuliahan seperti ujian semester serta proses penilaian masing-masing mata kuliah, kemudian dilanjutkan dengan pengolahan administrasi untuk yudisium sampai dengan proses wisuda, sehingga Smart Academic ini menjadi sistem informasi yang kritis bagi pihak Universitas apabila terjadi kegagalan maka akan menghambat proses perkuliahan yang artinya sistem ini tidak dapat memenuhi tujuannya. Selain itu sudah terdapat keluhan dalam penggunaan sistem informasi Smart Academic yang disampaikan oleh staf DAAK, dimulai dari beberapa fungsi yang sulit untuk dipahami, perkembangan masih berjalan lambat sehingga proses evaluasi ini dirasa sangat penting untuk dilakukan guna mengatahui seberapa baik sistem tersebut dalam memenuhi tujuannya untuk melakukan perbaikan kinerja dan pelayanan kedepannya.

Pengalaman pengguna merupakan salah satu indikator yang dapat digunakan untuk mengevaluasi sebuah sistem atau sering disebut User Experience. User Experience merangkum semua aspek emosi pengguna, keyakinan, keinginan, persepsi, respon fisik, psikologi, perilaku, dan pencapaian yang terjadi sebelum, saat dan setelah digunakan (ISO 9241-210:2010,2009). Sebuah sistem informasi seharusnya tidak hanya bisa digunakan, namun juga dapat membuat pengguna nyaman untuk menggunakan sistem tersebut. [1]. Pada penelitian yang dilakukan oleh [2], dipaparkan mengenai pengukuran pengalaman pengguna dalam menggunakan informasi akademik. Hasil penelitian menunjukkan bahwa efisiensi dalam penyelesaian tugas dan perasaan senang yang dirasakan ketika menggunakan Portal Akademik merupakan faktor yang dapat mempengaruhi keinginan pengguna untuk mennggunakan Portal Akademik. Hal ini dapat terjadi dikarenakan kemudahan yang dirasakan oleh pengguna tidak dapat dirasakan secara merata karena penggunaan Portal Akademik hanya pada waktu tertentu yaitu pada masa pengelolaan data nilai, hal ini dapat mengakibatkan ketersediaan Portal Akademik tidak dapat mempengaruhi keinginan pengguna dalam menggunakan sistem tersebut. [2]

Penelitian selanjutnya dilakukan oleh [3], mengenai Analisis dan Evaluasi Aspek Usability Pada Web HRMIS Telkom University Menggunakan usability testing. Hasil dari penelitian ini menunjukan bahwa aspek usability untuk meningkatkan kepuasan pengguna yang berpengaruh signifikan terhadapa kepuasana pengguna aplikasi HRMIS TelkomUniversity adalah Efficiency, dan Helpfulnss. [3], berdasarkan temuan-temuan penelitian tersebut maka penulis akan mencoba untuk melakukan penelitian tentang faktor-faktor apa saja yang mempengaruhi tingkat Usability sistem informasi Smart Academic, seberapa baik tingkat penggunaan sistem tersebut diukur melalui User Experience menggunakan pendekatan Usability Testing dengan metode Nielsen Heuristic.

Melalui penelitian ini diharapakan dapat menjadi rekomendasi dan berkontribusi bagi pengelola dalam mengembangkan layanan untuk dapat memenuhi kebutuhan informasi bagi pengguna sistem Smart Academic.

\section{TINJAUAN PUSTAKA}

Pada penelitian yang dilakukan oleh [2], mengenai pengukuran pengalaman pengguna dalam menggunakan sistem informasi akademik, adapun tujuan dari penelitian ini adalah untuk melihat faktor-faktor apa saja yang dapat mempengaruhi keinginan pengguna untuk menggunakan Portal akademik. Hasil dari analisis yang dilakukan menyatakan bahwa faktor-faktor yang dapat mempengaruhi keinginan pengguna untuk menggunakan portal akademik adalah efisiensi dalam penyelesaian tugas dan perasaan senang yang dirasakan oleh pengguna ketika menggunakan portal akademik. Kemudian pengujian hipotesis didasari oleh data yang dikumpulkan dengan penyebaran kuisioner ke 66 responden yang merupakan dosen dari seluruh fakultas yang ada di UNMUL dan pengolahan data di lakukan dengan menggunakan SmartPLS 3. [2] 
Penelitian yang dilakukan oleh [3], mengenai Analisis dan Evaluasi Aspek Usability Pada Web HRMIS Telkom University Menggunakan usability testing adapun tujuan penelitian ini adalah menghasilkan pengujian regresi linear berganda, seluruh aspek usability berpengaruh postif atau searah dengan kepuasan pengguna dan memberikan rekomendasi perbaikan untuk aplikasi HRMIS Telkom University berdasarkan aspek usability untuk meningkatkan kepuasan pengguna, aspek yang berpengaruh signifikan terhadap kepuasana pengguna aplikasi HRMIS Telkom University adalah Efficiency, dan Helpfulness. [3]. Penelitian yang dilakukan oleh [4], mengenai user experience produk iDigital museum dengan menggunakan User Experience Quitionnaire adapun hasil penelitian ini dapat disimpulkan bahwa fakta geologis Bandung Purba dapat diimplementasikan ke dalam aplikasi interaktif, serta aplikasi interaktif Bandung Purba cenderung memiliki impresi positif kelompok attractiveness, percpiculty, dependability, stimulation dan novelty dalam pengujian UEQ. Pengujian UEQ berupa kuesioner dengan 26 pertanyaan impresi atas produk yang diberika kepada pengunjung. Pengunjung diminta menjawab secara spontan, dalam waktu 25 hingga 30 menit. Jumlah pengunjung yang mengisi kuesioner adalah 10 orang. Masing-masing pertanyaan memiliki skala penilaian 1 sampai dengan 7. [4]. Pada penelitian yang dilakukan oleh [5], mengenai pengukuran evaluasi usability sistem informasi prakerin Pendidikan Teknik Informatika bertujuan untuk mengetahui evaluasi sistem informasi dari segi kegunaannya, keefektivan, keefisienan, dan kepuasan pengguna dalam menggunakan sistem informasi Prakerin PTI. Hasil penelitian diperolah 1. Sistem informasi Prakerin PTI masih belum efektif, karena masih ada error yang dilakukan responden mahasiswa atau dosen dalam melaksanakan tugas yang diberikan. Kemudian dilihat dari hasil penghitungan waktu pelaksaan tugas antara responden pemula atau mahir tidak terdapat perbedaan yang signifikan. Dari hasil rekapitulasi kuesioner SUS yang didapat dihitung dengan menggunakan perbandingan Mann Whitney U-Test hasilnya adalah untuk responden mahasiswa 62,08 dan responden dosen 60,42. [5]

Sedangkan pada penelitian ini akan mengkaji faktor-faktor yang mempengaruhi tingkat kegunaan/Usability, pengujian hipotesis didasari oleh data yang dikumpulkan dengan penyebaran kuesioner ke 8 responden yang merupakan pengelola bagian administrasi, , indikator kuesioner dibuat dengan menggunakan metode Nielsen Heuristic, dan pengolahan data dilakukan dengan menggunakan SPSS serta teknik evaluasi menggunakan Retrospective Think Aloud.

\section{METODE PENELITIAN}

Adapun alur penelitian yang digunakan dapat dilihat pada Gambar 1 berikut.

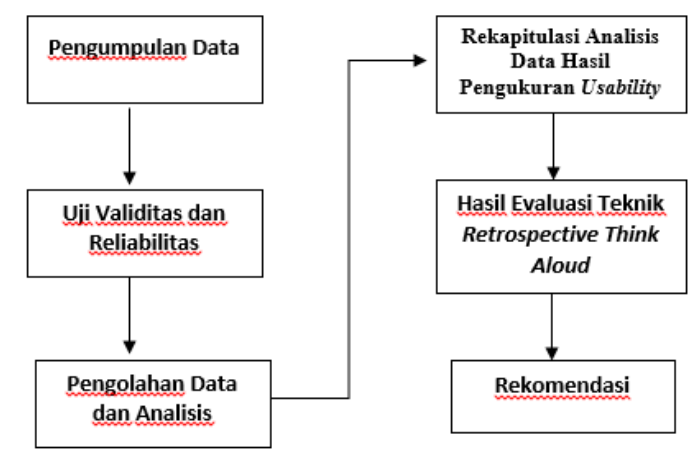

\subsection{Pengumpulan Data}

\section{Gambar 1. Alur Penelitian}

Pengumpulan data dengan metode wawancara, dan kuesioner (angket) berdasarkan variabelvariabel yang telah dirumuskan untuk penelitian ini. Dalam penelitian ini beberapa metode yang digunakan dalam pengumpulan data, antara lain : Studi pustaka, observasi, wawancara, dan kuesioner.

1. Studi Pustaka

Merupakan tahap pengumpulan sumber-sumber, wawasan dan pengetahuan mengenai permasalahan yang akan dibahas dan menentukan metode yang tepat untuk memecahkan masalah tersebut. Studi pustaka dapat ditelusuri melalui literatur berupa buku panduan, jurnal, hasil penelitian 
orang lain, serta pencarian informasi dari berbagai situs melalui internet maupun sumber-sumber lainnya seperti diskusi dengan dosen dan penulis.

2. Wawancara

Pada tahap ini penulis melakukan wawancara terhadap direktur bagian DAAK Universitas Amikom Yogyakarta sekaligus untuk memeperoleh keterangan mengenai objek penelitian dan berbagai kendala yang ada pada sistem yang sedang berjalan.

\section{Kuesioner}

Peneliti merancang kuesioner untuk mengetahui usability sistem informasi yang digunakan oleh DAAK Universitas Amikom Yogyakarta dengan melihat respon pengguna dalam menjalankan sistem informasi tersebut. Evaluasi pada penelitian ini menggunakan metode Retrospective Think Aloud yang dapat diuraikan sebagai berikut :

a. Memberikan tugas sesuai dengan 10 indikator Nielsen Heuristic untuk pengujian pada pengguna.

b. Evaluator diberikan tugas-tugas tertentu agar memudahkan dalam evaluasi.

c. Evaluasi dimulai ketika pengguna memasuki sistem dan melakukan evaluasi pada Smart Academic sesuai dengan tugas yang telah diberikan

d. Apabila evaluator menemukan permasalahan pada usability pada sistem, maka evaluator diminta untuk mencatat permasalahan tersebut di kolom komentar yang tersedia.

e. Evaluasi selesai.

Indikator kuesioner akan dibuat sesuai dengan panduan metode Nielsen Heuristic dengan melibatkan stakeholder yang ada. Kuesioner dalam penelitian ini akan berisi pertanyaan sesuai dengan metode Nielsen Heuristic yang dipakai dengan menguraikan masing-masing kriteria dengan poin pertanyaan. Adapun variable instrumen yang digunakan dalam penelitian ini dapat dilihat pada Tabel 1 berikut.

Tabel 1. Variabel Instrumen Penelitian

\begin{tabular}{|c|c|c|}
\hline Prinsip Heuristic & Indikator Variabel & Kode \\
\hline \multirow{3}{*}{$\begin{array}{l}\text { Visibility of System }(\mathrm{X} 1) \\
\text { Match between system and } \\
\text { the real world }(\mathrm{X} 2)\end{array}$} & Pesan umpan balik dalam waktu yang tepat & VOS 1 \\
\hline & Menu Informatif & MBS 1 \\
\hline & Penyajian Konten & MBS 2 \\
\hline \multirow{2}{*}{$\begin{array}{l}\text { User Control and Freedom } \\
\qquad(\mathrm{X} 3)\end{array}$} & Mekanisme jalan pintas/Shortcut & UCF 1 \\
\hline & Kemudahan setiap menu & UCF 2 \\
\hline $\begin{array}{l}\text { Consistency and Standards } \\
\text { (X4) }\end{array}$ & Sistem memiliki konsistensi pada setiap menu & CS 1 \\
\hline \multirow[t]{2}{*}{$\begin{array}{l}\text { Prevention Error System } \\
\text { (X5) }\end{array}$} & Mekanisme pencegahan kesalahan & PES 1 \\
\hline & Informasi Pesan kesalahan & PES 2 \\
\hline \multirow{3}{*}{$\begin{array}{c}\text { Recognition Rather Than } \\
\text { Recall (X6) } \\
\text { Flexibility and Efficient (X7) }\end{array}$} & Notifikasi pengingat pada sistem & RR1 \\
\hline & $\begin{array}{l}\text { Pengalaman pengguna dalam mengoperasikan } \\
\text { sistem }\end{array}$ & FEU 1 \\
\hline & Penyesuain pengguna dengan sistem & FEU 2 \\
\hline \multirow[t]{2}{*}{$\begin{array}{c}\text { Aesthetic and Minimalist } \\
\text { Design (X8) }\end{array}$} & Relevansi psan dialog pada sistem & AMD 1 \\
\hline & $\begin{array}{l}\text { Pesan dialog dengan sederhana dan simpel yang } \\
\text { memungkinkan pengguna melakukan tindakan }\end{array}$ & AMD 2 \\
\hline \multirow{2}{*}{$\begin{array}{c}\text { Help Users recognize, } \\
\text { dialogue, and recovers from } \\
\text { errors (X9) }\end{array}$} & $\begin{array}{l}\text { Pesan kesalahan dimunculkan dalam bahasa } \\
\text { yang sederhana }\end{array}$ & HER 1 \\
\hline & $\begin{array}{l}\text { Pesan kesalahan yang muncul konstruktif dan } \\
\text { memberikan alternatif solusi }\end{array}$ & HER 2 \\
\hline \multirow[t]{2}{*}{$\begin{array}{l}\text { Help and Documentation } \\
\qquad(\mathrm{X} 10)\end{array}$} & $\begin{array}{l}\text { Dokumentasi yang membantu dalam penggunaan } \\
\text { sistem }\end{array}$ & HED 1 \\
\hline & $\begin{array}{l}\text { Sistem informasi desertai dengan informasi yang } \\
\text { mudah dicari oleh pengguna }\end{array}$ & HED 2 \\
\hline
\end{tabular}




\section{HASIL DAN PEMBAHASAN}

Pada hasil dan pembahasan, dipaparkan mengenai data dari hasil kuesioner yang telah diisi oleh responden, adapun responden dalam penelitian ini adalah staff DAAK (Direktorat Administrasi Akademik dan Kemahasiwaan) Universitas Amikom Yogyakarta. Responden dalam penelitian ini sebanyak 8 orang dengan rincian 3 orang laki-laki dan 5 orang perempuan yang memberikan evaluasi pada sistem informasi Smart Academic dengan mengisi kuesioner yang merujuk pada evaluasi usability dengan heuristic. Simulasi dilakukan dengan mengakses sistem secara langsung untuk mendapatkan hasil yang lebih maksimal, kemudian simulasi sistem ini juga dilakukan untuk verifikasi dan memperkuat hasil evaluasi yang di dapat melalui sebaran kuesioner.

\subsection{Uji Validitas}

Uji validitas berfungsi untuk menguji apakah indikator-indikator pertanyaan yang digunakan dapat mengkonfirmasi sebuah konstruk atau variabel. Pengambilan keputusan untuk menentukan valid tidaknya instrument dilakukan dengan melihat hasil $r$-hitung dibandingkan $\mathrm{r}$-tabel dimana $\mathrm{df}=\mathrm{n}$ 2 (degree of freedom) dengan taraf signifikan 5\%, jika r-tabel < r-hitung maka dinyatakan valid. Dari rumus tersebut didapatkan $\mathrm{df}=8-2$ maka $\mathrm{df}=6$ maka uji validitas dinyatakan valid jika memiliki nilai faktor loading $>0,71$. [6]. Dengan menggunakan bantuan program SPSS, hasil pengujian dapat dilihat pada Tabel 2 berikut ini.

Tabel 2. Hasil Uji Validitas

\begin{tabular}{cccc}
\hline Butir Pertanyaan & R-hitung & R-tabel & Keterangan \\
\hline 1 & 0.898 & 0.71 & Valid \\
2 & 0.747 & 0.71 & Valid \\
3 & 0.788 & 0.71 & Valid \\
4 & 0.898 & 0.71 & Valid \\
5 & 0.726 & 0.71 & Valid \\
6 & 0.889 & 0.71 & Valid \\
7 & 0.788 & 0.71 & Valid \\
8 & 0.747 & 0.71 & Valid \\
9 & 0.896 & 0.71 & Valid \\
10 & 0.726 & 0.71 & Valid \\
11 & 0.726 & 0.71 & Valid \\
12 & 0.788 & 0.71 & Valid \\
13 & 0.788 & 0.71 & Valid \\
14 & 0.726 & 0.71 & Valid \\
15 & 0.726 & 0.71 & Valid \\
16 & 0.726 & 0.71 & Valid \\
17 & 0.788 & 0.71 & Valid \\
\hline
\end{tabular}

Berdasarkan hasil uji validitas dengan menggunakan SPSS 23 menunjukkan bahwa nilai r-hitung korelasi semua pertanyaan dari variabel lebih besar dari r-tabel. Hasil yang diperoleh dari semua item dinyatakan valid dan dapat digunakan sebagai alat pengumpulan data pada penelitian ini.

\subsection{Uji Reliabilitas}

Reliabilitas merupakan ukuran suatu kestabilan dan konsistensi responden dalam menjawab hal yang berkaitan dengan konstruk-konstruk pertanyaan yang merupakan dimensi suatu variabel dan disusun dalam suatu bentuk kuesioner. Untuk menguji reliabilitas kuesioner atau pertanyaan digunakan rumus Cronbach Alpha. Suatu kuesioner penelitian dinyatakan reliabel apabila koefisien reliabilitas ( $r$ alpha) lebih besar dari nilai r-tabel. Setelah diperoleh koefisien reliabilitas kemudian dikonsultasikan dengan tabel nilai $r$ dengan taraf signifikan 5\%. [6]

Sugiyono merumuskan cara menginterpretasikan koefisien r, dalam Tabel. 3 berikut ini. 
Tabel 3. Interpretasi Terhadap Koefisien Korelasi

\begin{tabular}{lll}
\hline No & Koefisien & Interpretasi \\
\hline 1 & 0.800 sampai dengan 1.00 & Sangat Kuat \\
2 & 0.600 sampai dengan 0.800 & Kuat \\
3 & 0.400 sampai dengan 0.600 & Sedang \\
4 & 0.200 sampai dengan 0.400 & Rendah \\
5 & 0.00 sampai dengan 0.200 & Sangat Rendah \\
\hline
\end{tabular}

Sedangkan hasil uji reliabilitas dapat dilihat pada Tabel 4. berikut ini.

\begin{tabular}{cc}
\multicolumn{2}{|c}{ Tabel 4. Hasil Reliability Statistics } \\
\hline $\begin{array}{c}\text { Cronbach's } \\
\text { Alpha }\end{array}$ & N of Items \\
\hline 0.961 & 17 \\
\hline
\end{tabular}

Hasil analisis menunjukkan bahwa nilai Cronbach's Alpha sebesar 0.961, angka tersebut melampaui nilai signifikasi 0.8 maka dapat disimpulkan insrumen dinyatakan reliabel dan dapat digunakan untuk pengujian selanjutnya. Nilai reliabilitas yang diperoleh 0.961 berada pada taraf interpretasi "Sangat kuat".

\subsection{Pengolahan Data dan Analisis}

Proses pengolahan data dibagi berdasarkan teknik pengambilan data yang dilakukan. Analisis akan dilakukan terhadap dua proses yang digunakan untuk mengukur usability Sistem informasi Smart Academic di DAAK Universitas AMIKOM Yogyakarta, selanjutnya akan ditarik kesimpulan terhadap hasil analisis yang mengacu pada hasil pengukuran usability dengan pendekatan Heuristic Model. Perhitungan data hasil kuesioner dilakukan dengan skala likert, terbagi dalam skala skor penilaian antara 1-4, dimana skor 1 untuk jawaban responden sangat tidak setuju sampai dengan skor 4 untuk jawaban sangat setuju, skala penilaian tersebut disajikan pada Tabel 5. [7]

Tabel 5. Skala Penilaian

\begin{tabular}{lll}
\hline Pernyataan & Disingkat & Skor \\
\hline Sangat Tidak Setuju & STS & 1 \\
Tidak Setuju & TS & 2 \\
Setuju & S & 3 \\
Sangat Setuju & SS & 4 \\
\hline
\end{tabular}

Dalam menghitung kriteria kelayakan, dilakukan dengan mengalikan nilai penilaian dengan jumlah skor penilaian dengan jumlah indicator yang diukur sesuai rumus: Persentase kelayakan tiap aspek $(\%)=\frac{\sum \text { rerataskoryang diperoleh }}{\sum \text { rerata skor ideal }} \times 100 \%$. Hasil dari pengalian tersebut kemudian dianalisis ke dalam distribusi nilai dan persentase dengan skala penilaian sesuai tabel 6. [10]

Tabel 6. Persentase Kelayakan Evaluasi Usability Smart Academic

\begin{tabular}{cc}
\hline $\begin{array}{c}\text { Persentase } \\
\text { penilaian }\end{array}$ & Kategori \\
\hline $75 \%-100 \%$ & Sangat Baik \\
$50 \%-74,9 \%$ & Baik \\
$25 \%-49,9 \%$ & Tidak Baik \\
$0 \%-24,9 \%$ & Sangat Tidak Baik \\
\hline
\end{tabular}


Perhitungan persentase jawaban responden dilakukan melalui distribusi frekuensi dan persentase menggunakan formula:

$$
P=\frac{f}{N} \times 100 \%
$$

Keterangan :

$\mathrm{P}=$ Persentase

$\mathrm{F}=$ Frekuensi Data

$\mathrm{N}=$ Jumlah Sampel Yang Diolah

Tabel 7. Hasil Pengolahan Kuesioner

\begin{tabular}{|c|c|c|c|c|c|c|}
\hline \multirow{3}{*}{ Kode } & \multicolumn{4}{|c|}{ Skala Likert } & \multirow{3}{*}{ Total } & \multirow{3}{*}{$\begin{array}{c}\text { Index } \\
\text { Persentase }\end{array}$} \\
\hline & 1 & 2 & 3 & 4 & & \\
\hline & STS & TS & $\mathbf{S}$ & SS & & \\
\hline VOS 1 & 0 & 0 & 12 & 16 & 28 & 87.5 \\
\hline MBS 1 & 0 & 0 & 15 & 12 & 27 & 84.4 \\
\hline MBS 2 & 0 & 0 & 18 & 8 & 26 & 81.3 \\
\hline UCF 1 & 0 & 0 & 21 & 4 & 25 & 78.1 \\
\hline UCF 2 & 0 & 0 & 24 & 0 & 24 & 75.0 \\
\hline CS 1 & 0 & 6 & 12 & 4 & 22 & 68.8 \\
\hline PES 1 & 0 & 8 & 12 & 0 & 20 & 62.5 \\
\hline PES 2 & 0 & 4 & 12 & 8 & 24 & 75.0 \\
\hline RR1 & 0 & 0 & 18 & 8 & 26 & 81.3 \\
\hline FEU 1 & 0 & 0 & 15 & 12 & 27 & 84.4 \\
\hline FEU 2 & 0 & 4 & 9 & 12 & 25 & 78.1 \\
\hline AMD 1 & 0 & 0 & 21 & 4 & 25 & 78.1 \\
\hline AMD 2 & 0 & 2 & 21 & 0 & 23 & 71.9 \\
\hline HER 1 & 0 & 0 & 21 & 4 & 25 & 78.1 \\
\hline HER 2 & 0 & 0 & 18 & 8 & 26 & 81.3 \\
\hline HED 1 & 0 & 8 & 12 & 0 & 20 & 62.5 \\
\hline HED 2 & 0 & 0 & 21 & 4 & 25 & 78.1 \\
\hline Rata-rata & 0 & 1.88 & 16.59 & 6.12 & 24.59 & 76.84 \\
\hline
\end{tabular}

Berdasarkan analisis yang dilakukan dengan metode Heuristic Evaluation diperoleh frekuensi kategori sebagai berikut:

1. Visibility of System

Sistem harus selalu memberikan informasi kepada pengguna apa yang sedang berlangsung melalui pesan umpan balik dalam waktu yang tepat. Meninjau pada tabel 7. Hasil pengolahan kuesioner analisis reponden pada variabel Visibility of System diperoleh hasil penilaian sangat baik dengan persentase $87.5 \%$. Sebanyak $57 \%$ responden menyatakan sistem menyediakan visibilitas sehingga pengguna mengetahui status dan aksi alternatif yang bisa dipilih.

2. Match Between System and The Real World

Berdasarkan hasil analisis data pada tabel 7. terhadap variabel Match Between System and The Real World dapat dilihat bahwa pada indikator MBS 1 diperoleh persentase sebesar $84.4 \%$ sedangkan indikator MBS 2 sebesar 81.3\%. Hasil pengolahan rerata persentase pada variabel Match Between System and The Real World diperoleh hasil persentase $83 \%$ yang menyatakan variabel ini memiliki tingkat usability yang sangat baik. Indikator MBS 1 menunjukkan 56\% responden setuju sistem sudah menyajikan informasi yang sesuai pada setiap halaman, sedangkan pada indikator MBS 2 menunjukkan $69 \%$ responden sangat setuju sistem informasi menyajikan konten yang mudah dipahami. 


\section{User Control and Freedom}

Berdasarkan hasil analisis data pada tabel 7. terhadap variabel User Control and Freedom dapat dilihat bahwa pada indikator UCF 1 diperoleh presentase sebesar 84\%, sedangkan pada indikator UCF 2 diperoleh persentase 69\%. Dari tabulasi indikator tersebut diperoleh rerata persentase $77 \%$ pada variabel User Control And Freedom, dari tabulasi tersebut menyatakan variabel ini memiliki tingkat usability yang sangat baik. Indiktor UCF 1 menunjukkan $84 \%$ responden setuju bahwa Sistem Informasi Smart Academic sudah dilengkapi dengan mekanisme jalan pintas atau shortcut untuk menuju halaman tertentu yang diinginkan pengguna, sedangkan pada indikator UCF 2 menunjukkan bahwa 69\% responden setuju jika Sistem Informasi Smart Academic memberikan panduan yang jelas untuk menjelajah setiap menu yang ada.

4. Consistency and Standards

Berdasarkan hasil analisis pada tabel 7. terhadap variabel Consistency and Standards diperoleh hasil penilaian yang baik dengan persentase 68,8\%. Variabel Consistency and Standards menunjukkan 55\% responden menilai bahwa dalam menggunakan Sistem Informasi Smart Academic tidak perlu bertanya kepada siapapun dan langsung bisa menggunakannya. Sedangkan $27 \%$ responden menilai bahwa dalam mengakses sistem pengguna harus bertanya kepada orang lain karena pada sistem informasi Smart Academic tidak ada menu help/bantuan.

5. Preventive Error System

Berdasarkan hasil analisis data pada tabel 7. terhadap variabel Preventive Error System menunjukkan bahwa pada indikator PES1 diperoleh persentase 62,5\%, sedangkan indikator PES 2 diperoleh persentase sebesar 75\%. Dari tabulasi indikator tersebut diperoleh rerata persentase $68,8 \%$. Pada variabel Preventive Error System, dari tabulasi tersebut menyatakan variabel ini memiliki tingkat usability yang baik. Indikator PES 1 memiliki persentase $60 \%$ yang menyatakan bahwa sistem sudah disertai dengan mekanisme pencegahan agar pengguna tidak melakukan kesalahan dalam entri data sedangkan $40 \%$ responden menyatakan tidak setuju bahwa Sistem Informasi Smart Academic sudah disertai dengan mekanisme pencegahan agar pengguna tidak melakukan kesalahan dalam entri data. Sedangkan pada indikator PES $250 \%$ responden menyatakan bahwa Sistem Informasi Smart Academic sudah menyajikan pesan kesalahan yang informatif apabila pengguna melakukan input data yang tidak sesuai.

6. Recognation Rather Than Recall

Berdasarkan tabel 7. hasil pengelolaan kuesioner analisis responden pada variabel Recognation Rather Than Recall diperoleh hasil penilaian sangat baik dengan persentase 81,3\%. Sistem Informasi Smart Academic sudah memiliki pengingat/notifikasi saat pengguna melewatkan sebuah data dengan persentase $69 \%$.

7. Flexibelity And Efficient of Use

Berdasarkan hasil analisis pada tabel 7. terhadap variabel Flexibelity And Efficient of Use menunjukkan bahwa indikator FEU 1 diperoleh persentase sebesar $84,4 \%$. Sedangkan indikator FEU 2 diperoleh persentase $78,1 \%$. Dari tabulasi indikator tersebut diperoleh rerata persentase $81,3 \%$ pada variabel Flexibelity And Efficient Of Use, dari tabulasi tersebut menyatakan bahwa variabel ini memiliki tingkat Usability sangat baik. Sistem Informasi Smart Academic mudah digunakan baik untuk pemula maupun pengguna yang sudah berpengalaman dengan persentase $56 \%$. Sedangkan pada indikator FEU 2, 48\% responden menilai bahwa Sistem Informasi Academic efisien untuk digunakan oleh pengguna tanpa membutuhkan waktu yang lama. Sedangkan $16 \%$ responden menyatakan tidak setuju.

\section{Aesthetic And Minimalist Design}

Berdasarkan hasil analisis data pada tabel 7. terhadap variabel Aesthetic And Minimalist Design menunjukkan bahwa pada indikator AMD 1 diperoleh persentase sebesar 78,1\% sedangkan pada indikator AMD 2 diperoleh persentase sebesar 71,9\%. Dari tabulasi indikator tersebut diperoleh rerata persentase $75 \%$ pada variabel Aesthetic And Minimalist Design yang artinya variabel ini sudah memiliki tingkat Usability yang sangat baik. Sistem memberikan pesan dialog yang relevan dan dibutuhkan dengan persentase $84 \%$. Sedangkan pada indikator AMD 2, 91\% responden menilai bahwa sistem sudah memberikan pesan dialog yang sederhana, simpel dan tidak membingungkan. Sebaliknya $9 \%$ responden menyatakan tidak setuju.

9. Help, Users Recognize, Dialogue, and Recovers From Errors 
Berdasarkan hasil analisis data pada tabel 7. terhadap variabel Help, Users Recognize, Dialogue, and Recovers From Errors menunjukkan bahwa pada indikator HER 1 diperoleh persentase sebesar 78,1\%, sedangkan HER 2 diperoleh persentase 81,3\%. Dari tabulasi indikator tersebut diperoleh rerata persentase sebesar $80 \%$ pada variabel Help, Users Recognize, Dialogue, and Recovers From Errors yang artinya variabel ini sudah memiliki tingkat Usability yang sangat baik. Indikator HER 1 dimana pesan kesalahan pada sistem dimunculkan dalam bahasa yang sederhana dan mudah untuk dipahami dengan persentase sebesar 84\%. Sedangkan pada indikator HER 2 responden menilai bahwa pesan kesalahan yang muncul pada sistem informasi Smart Academic bersifat konstruktif dan memberikan solusi dengan persentase sebesar $69 \%$ dari jumlah keseluruhan responden.

10. Help And Documentation

Berdasarkan hasil analisis pada tabel 7. terhadap variabel Help And Documentation dapat dilihat bahwa pada indikator HED 1 diperoleh persentase sebesar 62,5\%, sedangkan indikator HED 2 diperoleh persentase sebesar 78,1\%. Dari tabulasi indikator tersebut diperoleh rerata persentase 70,3\% pada variabel Help And Documentation yang artinya variabel ini sudah memiliki tingkat Usability yang sangat baik. Indikator HED 1, terdapat menu help pada Sistem Informasi Smart Academic yang dapat membantu pengguna, dengan persentase 60\% yang menyatakan setuju dan terdapat $40 \%$ responden menyatakan tidak setuju. Sedangkan pada indikator HED 2 terdapat $84 \%$ responden menyatakan setuju bahwa Sistem Informasi Smart Academic disertai dengan sitemap yang memudahkan pengguna melihat menu secara keseluruhan.

\subsection{Rekapitulasi Analisis Data Hasil Pengukuran Usability}

Berikut merupakan rekapitulasi analisis data hasil pengukuran Usability yang ditunjukkan pada tabel 8 .

Tabel 8. Rekapitulasi Analisis Data Hasil Pengukuran Usability

\begin{tabular}{|c|c|c|c|c|c|c|c|c|c|c|c|c|c|c|c|c|c|c|c|}
\hline Skala & Vo & Mbs & Mbs & Uc & Uc & Cs & $\mathbf{P e}$ & $\mathbf{P e}$ & $\mathbf{R r}$ & $\mathbf{F u}$ & $\mathbf{F e}$ & Amd & Amd & $\mathrm{He}$ & $\mathrm{He}$ & $\mathrm{He}$ & $\mathrm{He}$ & Rata & Respo \\
\hline Likert & s 1 & 1 & 2 & f 1 & f 2 & $\mathbf{1}$ & s 1 & s 2 & 1 & e 1 & u 2 & 1 & 2 & r 1 & r 2 & d 1 & d 2 & -rata & nden \\
\hline 4 & 16 & 12 & 8 & 4 & 0 & 4 & 0 & 8 & 8 & 12 & 12 & 4 & 0 & 4 & 8 & 0 & 4 & 6,12 & 32 \\
\hline 3 & 12 & 15 & 18 & 21 & 24 & 12 & 12 & 12 & 18 & 15 & 9 & 21 & 21 & 21 & 18 & 12 & 21 & $\begin{array}{c}16,5 \\
9\end{array}$ & 24 \\
\hline 2 & 0 & 0 & 0 & 0 & 0 & 6 & 8 & 4 & 0 & 0 & 4 & 0 & 2 & 0 & 0 & 8 & 0 & 1,88 & 16 \\
\hline 1 & 0 & 0 & 0 & 0 & 0 & 0 & 0 & 0 & 0 & 0 & 0 & 0 & 0 & 0 & 0 & 0 & 0 & 0,00 & 8 \\
\hline Total & 28 & 27 & 26 & 25 & 24 & 22 & 20 & 24 & 26 & 27 & 25 & 25 & 23 & 25 & 26 & 20 & 25 & $\begin{array}{c}24,5 \\
9\end{array}$ & \\
\hline Index & $\begin{array}{c}87, \\
5\end{array}$ & $\begin{array}{c}84,3 \\
8\end{array}$ & $\begin{array}{c}81,2 \\
5\end{array}$ & $\begin{array}{c}78, \\
13\end{array}$ & $\begin{array}{l}75, \\
00\end{array}$ & $\begin{array}{l}68, \\
75\end{array}$ & $\begin{array}{l}62, \\
50\end{array}$ & $\begin{array}{l}75, \\
00\end{array}$ & $\begin{array}{l}81, \\
25\end{array}$ & $\begin{array}{l}84 \\
38\end{array}$ & $\begin{array}{l}78 \\
13\end{array}$ & $\begin{array}{c}78,1 \\
3\end{array}$ & $\begin{array}{c}71,8 \\
8\end{array}$ & $\begin{array}{c}78, \\
13\end{array}$ & $\begin{array}{l}81, \\
25\end{array}$ & $\begin{array}{l}62 \\
50\end{array}$ & $\begin{array}{c}78, \\
13\end{array}$ & $\begin{array}{c}76,8 \\
4\end{array}$ & \\
\hline
\end{tabular}

Rekapitulasi analisis data hasil pengukuran Usability pada tabel 8. di masing-masing variabel diatas didapatkan dari nilai baik skala likert $X$ jumlah responden yang menjawab pada masing-masing variabel. Untuk variabel yang nilainya dibawah 24 diberi warna kuning dan selanjutnya dilakukan evaluasi.

Kalkulasi hasil rata-rata dari 10 variabel metode Heuristic Evaluation, maka didapatkan hasil rata-rata $76,8 \%$ yang dapat dibulatkan menjadi $77 \%$ dengan tingkat persentase tersebut Sistem Informasi Smart Academic berada pada tingkat Usability yang sangat baik dan sudah dapat memenuhi kriteria Usability pada sebuah sistem informasi berdasarkan persentase kelayakan evaluasi Usability. Batas baik sistem yang akan di evaluasi dihitung dengan melihat total yang memiliki interval baik, dengan rumus (total responden) $\mathrm{x}$ (skala likert batas baik) yaitu (8) $\mathrm{x}(3)=24$. Pada Tabel 4.6. terlihat bahwa system dinyatakan tidak perlu dilakukan perbaikan apabila nilai total melebihi angka minimal batas baik yaitu 24 dan tidak perlu dilakukan evaluasi. Grafik hasil evaluasi Sistem Informasi Smart Academic dapat dilihat pada Gambar 2. 


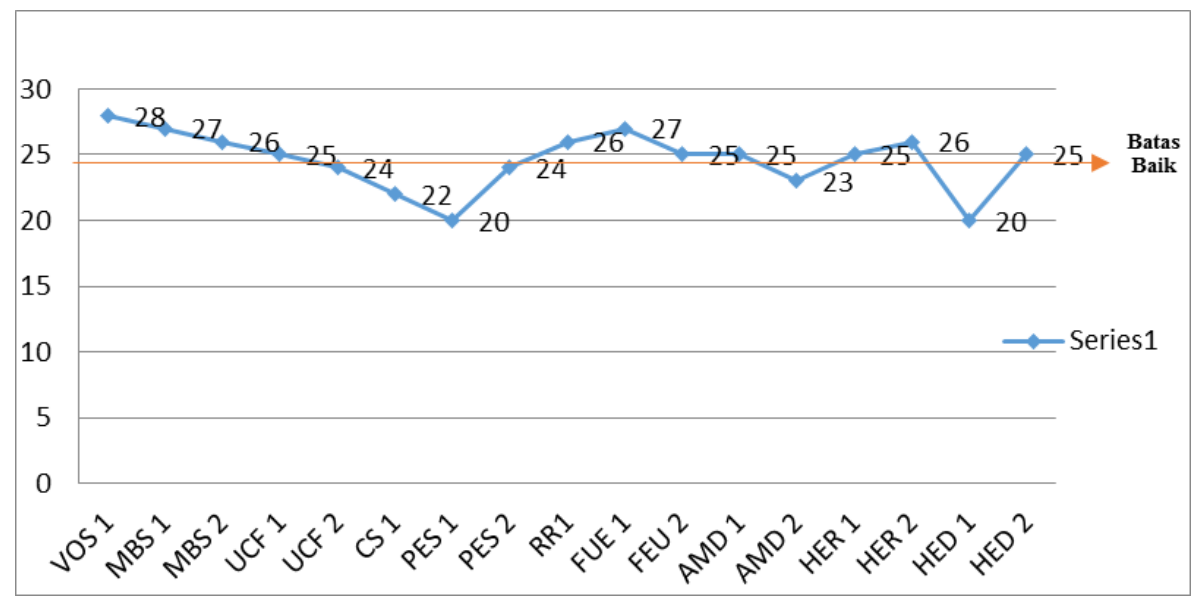

Gambar 2. Grafik hasil evaluasi

Berdasarkan Gambar 2. dapat diketahui bahwa dari 17 indikator yang ada, sebanyak 4 indikator memiliki total nilai dibawah 24 , sehingga indikator tersebut dijadikan pedoman dan dilakukan evaluasi dengan teknik Retrospective Think Aloud. Evaluasi ini bertujuan untuk memperkuat hasil yang didapatkan dari data kuesioner sebelumnya. Sehingga peneliti dapat memberikan usulan perbaikan sesuai dengan kebutuhan pengguna dan standard Usability yang ada.

\subsection{Hasil Evaluasi Teknik Retrospective Think Aloud}

Data hasil pengolahan dengan teknik Retrospective Think Aloud adalah data verbal yang didapatkan berupa komentar dari masing-masing responden. Data diperoleh dengan cara responden melakukan akses terhadap sistem secara langsung dan melakukan perintah sesuai langkah-langkah evaluasi yang telah disiapkan. Adapun hasil evaluasi yang dilakukan menggunakan Retrospective Think Aloud adalah berikut ini.

\section{Consistency And Standard}

Sistem yang baik pada konsep heuristic seharusnya pengguna tidak perlu mempertanyakan mengenai perbedaan pemahaman pada sebuah kata, kalimat, situasi dan aksi. Evaluasi yang dilakukan responden ditemukan bahwa button tutup di setiap menu yang terdapat pada Sistem Informasi Smart Academic terletak pada pojok kanan bawah sehingga button ini tidak mudah terjangkau oleh penglihatan pengguna. Serta di beberapa form terdapat button Proses yang pengguna sendiri masih mengalami kebingungan terkait fungsi button tersebut apakah dipergunakan untuk menyimpan data atau melakukan proses lainnya.

\section{Preventive Error System}

Pencegahan kesalahan seharusnya dilakukan sebelum pengguna melakukan simpan pada data yang sudah di inputkan, sehingga pengguna tidak melakukan pekerjaan berulang kali. Sistem tidak memberikan button edit dan hapus pada form bagi kelas sehingga pada saat pengguna salah melakukan input data pembagian kelas maka proses ini harus diulangi dari awal.

3. Aesthetic And Minimalist Design

Evaluasi yang dilakukan responden pada halaman form hapus nilai transkip. Ditemukan bahwa pada satu halaman terdapat button yang sama yang terdapat pada bagian tengah dan bawah. Button yang fungsinya sama dalam sebuah sistem dirasa sangat tidak efektif dan dapat membuat bingung pengguna sistem.

\section{Help And Documentation}

Evaluasi yang dilakukan responden dinyatakan bahwa tidak ditemukannya menu help dan juga fitur panduan dalam penggunaan sistem yang terdapat pada Smart Academic sehingga pada saat mengalami kesulitan pengguna harus menghubungi pihak pembuat sistem.

Kesimpulan evaluasi yang dilakukan menggunakan Retrospective Think Aloud dapat dilihat pada tabel 9 . 
Tabel 9. Rekapitulasi Analisis Data Hasil Pengukuran Usability

\begin{tabular}{|c|c|c|c|}
\hline NO & RESPONDEN & VARIABEL & KOMENTAR \\
\hline 1 & Admin & $\begin{array}{l}\text { Consistancy And } \\
\text { Standards }\end{array}$ & $\begin{array}{l}\text { 1. Button tutup terletak pada pojok kanan bawah dinilai sulit } \\
\text { untuk dijangkau. } \\
\text { 2. Tidak terdapat interface loading pada saat melakukan export } \\
\text { file ke excel. } \\
\text { 3. Terdapat button Proses pada beberapa form yang fungsinya } \\
\text { kurang dipahami oleh pengguna. }\end{array}$ \\
\hline 2 & Admin & $\begin{array}{l}\text { Preventive Error } \\
\text { System }\end{array}$ & $\begin{array}{l}\text { 1. Tidak terdapat button Edit dan hapus pada Form Bagi Kelas } \\
\text { di Sistem Informasi Smart Academic } \\
\text { 2. Pesan kesalahan ditampilkan setelah pengguna memilih } \\
\text { aksi } \\
\text { 3. Sistem tidak memberikan peringatan pada saat pengguna } \\
\text { memilih button simpan dan hapus. }\end{array}$ \\
\hline 3 & Admin & $\begin{array}{l}\text { Aesthetic And } \\
\text { Minimalist Design }\end{array}$ & 1. Terdapat button yang sama pada sebuah halaman \\
\hline 4 & Admin & $\begin{array}{l}\text { Help And } \\
\text { Documentation }\end{array}$ & $\begin{array}{l}\text { 1. Sistem Informasi Smart Academic tidak mempunyaimenu } \\
\text { Help/Bantuan } \\
\text { 2. Sistem Informasi Smart Academic tidak mempunyai } \\
\text { panduan dalam mengoperasikan sistem }\end{array}$ \\
\hline
\end{tabular}

\subsection{Usulan Perbaikan}

Dari evaluasi yang dilakukan dengan menggunakan teknik RTA didapatkan beberapa usulanusulan perbaikan yang dapat digunakan sebagai acuan dalam perbaikan sistem, usulan perbaikan diharapkan dapat memberikan kemudahan kepada pengguna sehingga dapat meningkatkan nilai Usability pada Sistem Informasi Smart Academic. Adapun usula perbaikan yang didapatkan dari hasil Evaluasi menggunakan teknik RTA dapat dilihat pada tabel 10 berikut.

Tabel 10. Rekapitulasi Analisis Data Hasil Pengukuran Usability

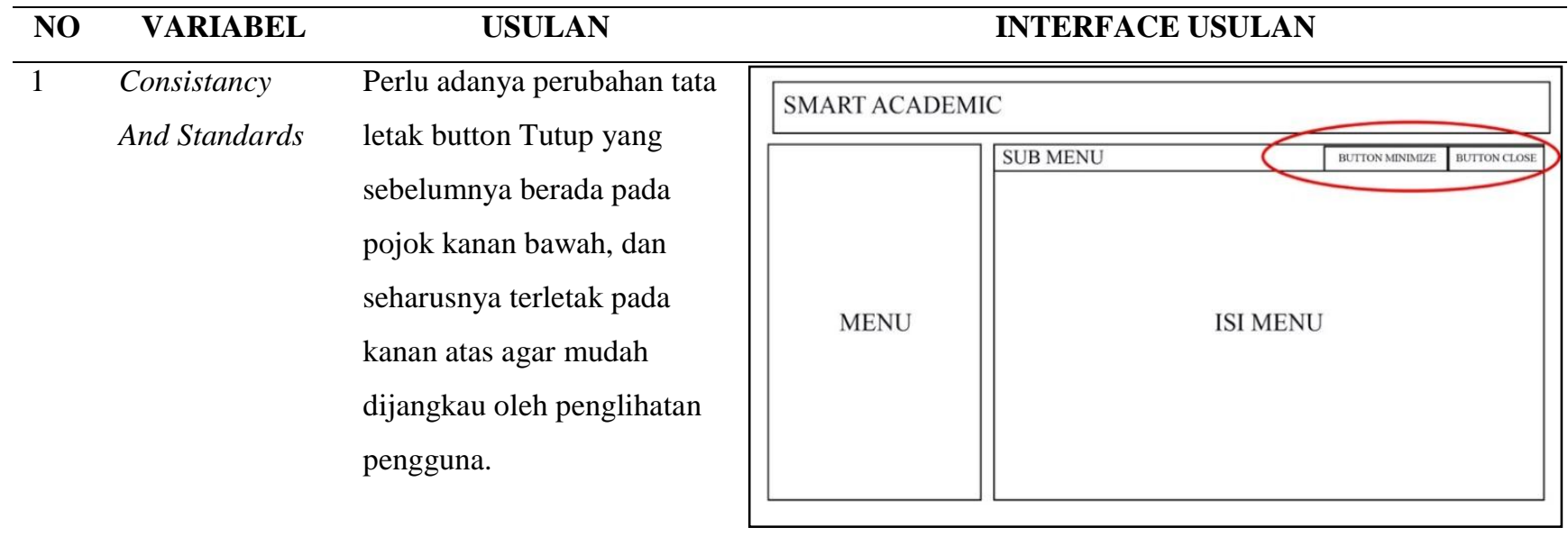


2

Consistancy
And Standards

Perlu ditambahkan interface loading agar pengguna dapat mengetahui proses secara detail pada saat melakukan export file excel.

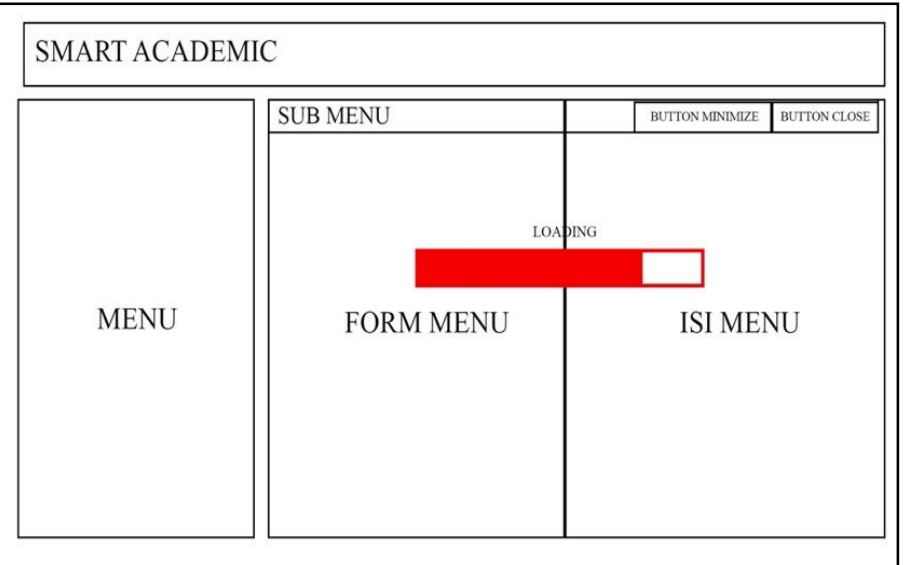

3
Consistancy

And Standards

4

5

\section{Preventive \\ Error System}

Error System
Perlu dilakukan penjabaran terkait maksud dari button

Proses pada beberapa form yang terdapat di sistem informasi smart academic. Perlu adanya penambahan button Edit dan Hapus pada form bagi kelas agar memudahkan pengguna untuk mengantisipasi terjadinya kesalahan agar tidak mengulangi proses dari awal.

Perlu adanya kotak dialog konfirmasi ketika pengguna melakukan aksi simpan atau hapus agar pengguna benarbenar mengetahui proses apa yang akan mereka lakukan.
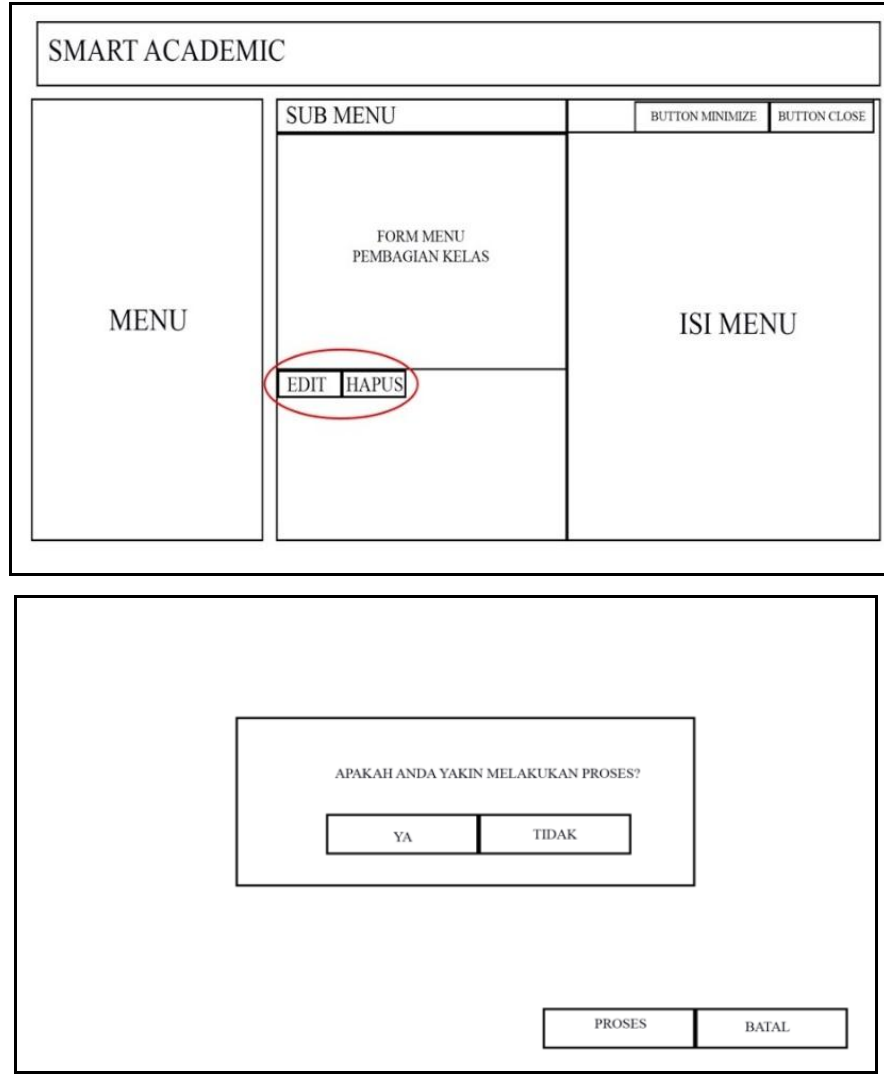
6 Aesthetic And Minimalist Design

7

$\begin{array}{ll}\text { Help And } & \text { Perlu adanya menu } \\ \text { Documentation } & \text { help/bantuan. }\end{array}$

8

Help And

Documentation sistem.
Seharusnya hanya terdapat satu button yang memiliki fungsi sama dalam sebuah form agar pengguna tidak mengalami kebingungan pada saat menggunakan
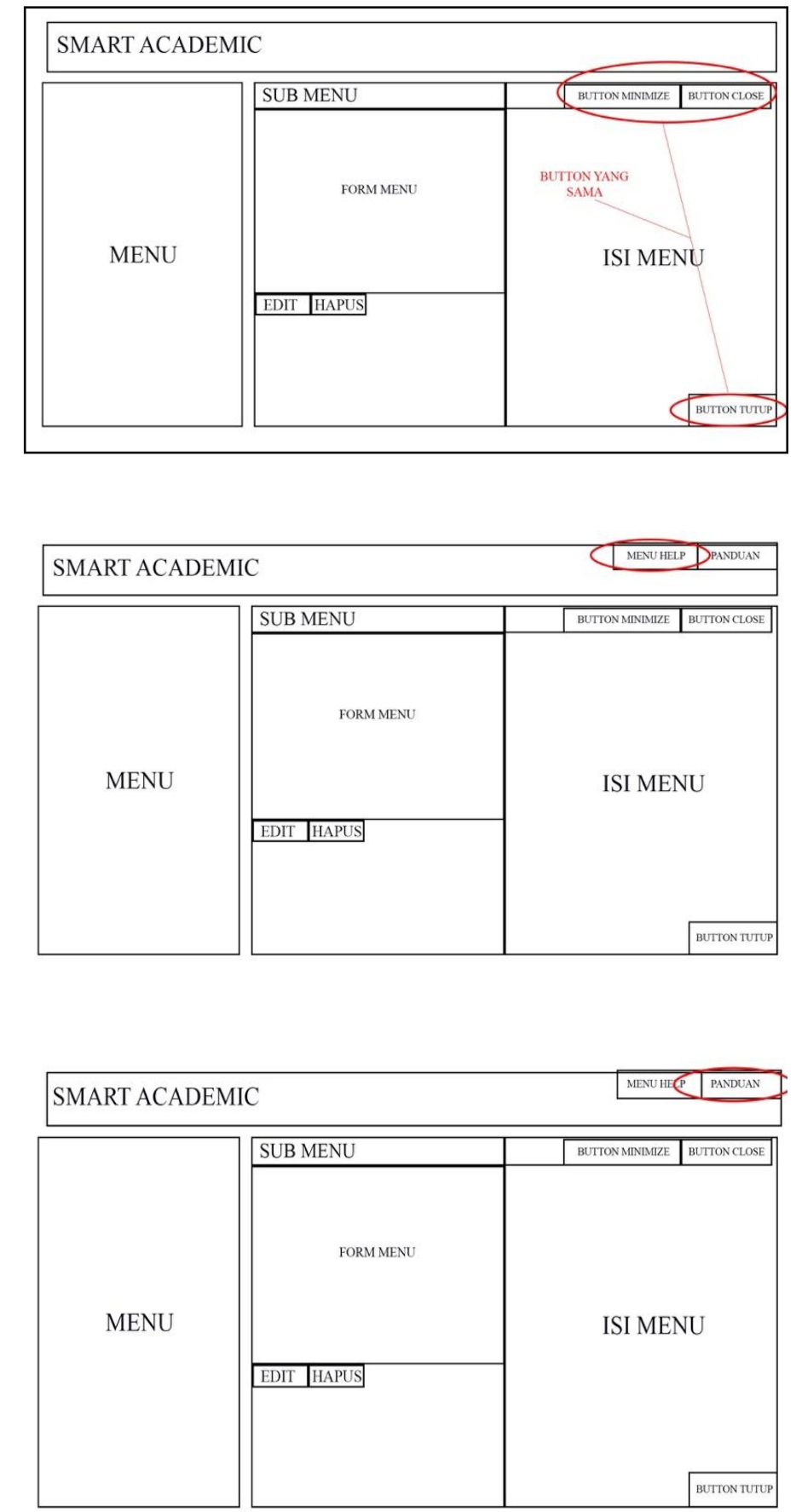

Selain rekomendasi pada tabel 10 di atas peneliti juga mengusulkan agar sistem informasi Smart Academic dapat terintegrasi dengan seluruh sistem yang ada di Universitas AMIKOM Yogyakarta agar lebih mempermudah keseluruhan administrasi pada semua bagian terkait. Selain itu peneliti juga mengusulkan desain antar muka untuk pengembangan sistem informai Smart Academic yang dapat dilihat pada table 10 .

\section{KESIMPULAN}

Berdasarkan hasil analisis data dan pembahasan tentang Evaluasi Usability pada Sistem Informasi Smart Academic dapat disimpulkan bahwa secara keseluruhan diperoleh hasil evaluasi dengan nilai persentase sebesar $77 \%$ dengan tingkat persentase tersebut Sistem Informasi Smart Academic berada pada tingkat Usability yang sangat baik dan sudah dapat memenuhi kriteria 
Usability pada sebuah sistem informasi. Kemudian dari 10 variabel Nielsen Heuristic masih terdapat 4 variabel Usability yang memiliki nilai kurang baik yaitu pada variabel Consistancy And Standards yang dapat dilihat pada hasil evaluasi dimana pengguna masih mengalami kebingungan terkait fungsi button dibeberapa form, Preventive Error System yang dapat dilihat pada hasil evaluasi dimana sistem tidak memberikan button edit dan hapus pada form bagi kelas sehingga pada saat pengguna salah melakukan input data maka proses ini harus diulangi dari awal, Aesthetic And Minimalist Design yang dapat dilihat pada hasil evaluasi terdapat button yang fungsinya sama dalam sebuah form sehingga dirasa sangat tidak efektif dan dapat menimbulkan kebingungan untuk pengguna sistem, Help And Documentation yang dapat dilihat pada hasil evaluasi tidak terdapat tombol help dan juga fitur panduan dalam penggunaan sistem, sehingga apabila mengalami kesulitan pengguna harus menghubungi pihak pembuat sistem.

Selanjutnya rekomendasi yang dapat diberikan untuk perbaikan sistem kedepan adalah pada bagian Consistancy And Standards perlu adanya perubahan tata letak button tutup yang sebelumnya berada pada pojok kanan bawah, dan seharusnya terletak pada kanan atas agar mudah dijangkau oleh penglihatan pengguna, Perlu ditambahkan interface loading agar pengguna dapat mengetahui proses secara detail pada saat melakukan export file excel.lalu pada bagian Preventive Error System Perlu adanya penambahan button Edit dan Hapus pada form bagi kelas agar memudahkan pengguna untuk mengantisipasi terjadinya kesalahan agar tidak mengulangi proses dari awal, kemudian Perlu adanya kotak dialog konfirmasi ketika pengguna melakukan aksi simpan atau hapus agar pengguna benarbenar mengetahui proses apa yang akan mereka lakukan. Selanjutnya pada bagian Aesthetic And Minimalist Design Seharusnya hanya terdapat satu button yang memiliki fungsi sama dalam sebuah form agar pengguna tidak mengalami kebingungan pada saat menggunakan sistem. Yang terakhir pada bagian Help And Documentation Perlu adanya menu help/bantuan dan Perlu adanya panduan pengoprasian sistem informasi smart academic.

\section{REFERENSI}

[1] M. Hassenzahl and N. Tractinsky, "User experience - A research agenda," Behav. Inf. Technol., vol. 25, no. 2, pp. 91-97, 2006, doi: 10.1080/01449290500330331.

[2] P. N. Lestari, P. I. Santosa, and R. Ferdiana, "Pengukuran Pengalaman Pengguna Dalam Menggunakan Sistem Informasi Akademik," Semin. Nas. Teknol. Inf. dan Komun., vol. 2016, no. Sentika, pp. 2089-9815, 2016, [Online]. Available: https://fti.uajy.ac.id/sentika/publikasi/makalah/2016/53.pdf.

[3] A. Sriwulandari, H. Hidayati, and B. Pudjoatmojo, "Analisis dan Evaluasi Aspek Usability Pada Web HRMIS Telkom University Menggunakan Usability Testing Analysis and Evaluation of Usability Aspects on Web HRMIS Telkom University Using Usability Testing,” e-Proceeding Eng., vol. 1, no. 1, pp. 537-542, 2014.

[4] A. Sularsa and A. S. Prihatmanto, "Evaluasi User Experiences Produk iDigital Museum dengan Menggunakan UEQ," J. Teknol. Inf., vol. 2, no. 2, pp. 56-62, 2015.

[5] D. A. P. A. Widhiani, I. K. R. Arthana, and I. M. A. Pradnyana, "Analisa User Experience Pada Sistem Informasi Akademik Universitas Pendidikan Ganesha Ditinjau dari Pengguna Mahasiswa," J. Pendidik. Teknol. dan Kejuru., vol. 15, no. 1, 2018, doi: 10.23887/jptkundiksha.v15i1.13048.

[6] K. M. Utamaningrum, W. Andhyka, and E. D. Wahyuni, "Analisa Pendekatan User Experience dan Psikologi Kognitif Terhadap Kenyamanan Pengguna Sistem Informasi KRSOnline Sebagai Bahan Evaluasi dan Pengembangan Sistem," JOINCS (Journal Informatics, Network, Comput. Sci., vol. 1, no. 1, p. 21, 2017, doi: 10.21070/joincs.v1i1.801.

[7] V. Intanny, I. Widiyastuti, M. Dolorosa, and K. Perdani, "Pengukuran Kebergunaan dan Pengalaman Pengguna Marketplace Jogjaplaza . id dengan Metode UEQ dan USE Questionnaire," Pekommas, vol. 3, no. 2, pp. 117-126, 2018, [Online]. Available: https://media.neliti.com/media/publications/267627-measuring-usability-and-user-experiencea292205a.pdf.

[8] E. L. C. Law, A. P. O. S. Vermeeren, M. Hassenzahl, and M. Blythe, "Towards a UX manifesto," People Comput. XXI HCI.But Not as We Know It - Proc. HCI 2007 21st Br. HCI Gr. Annu. Conf., vol. 2, no. September, pp. 3-5, 2007, doi: 10.14236/ewic/hci2007.95. 
[9] V. W. Sujarweni and L. R. Utami, “Analisis Dampak Pembiayaan Dana Bergulir KUR (Kredit Usaha Rakyat) Terhadap Kinerja UMKM (Studi Kasus di Daerah Istimewa Yogyakarta),” J. Bisnis dan Ekon. (JBE), vol. 22, no. 1, pp. 11-25, 2015.

[10] A. Sadnyana, M. Dharmawiguna, and A. Pradnyana, "Di Universitas Pendidikan Ganesha," Kumpul. Artik. Mhs. Pendidik. Tek. Inform., vol. 6, no. 2, pp. 309-319, 2017.

[11] U. E. Unggul, "Universitas Esa Unggul,” no. April, pp. 1-11, 2019. 